\title{
Possible role of $A B O$ system in age-related diseases and longevity: a narrative review
}

\author{
Claudia Rizzo ${ }^{1,2^{*}}$, Calogero Caruso ${ }^{1,2}$ and Sonya Vasto 3,4
}

\begin{abstract}
ABO blood group antigens are expressed either on the surface of red blood cells either on a variety of other cells. Based on the available knowledge of the genes involved in their biosynthesis and their tissue distribution, their polymorphism has been suggested to provide intraspecies diversity allowing to cope with diverse and rapidly evolving pathogens. Accordingly, the different prevalence of $A B O$ group genotypes among the populations has been demonstrated to be driven by malaria selection. In the similar manner, a particular ABO blood group may contribute to favour life-extension via biological mechanisms important for surviving or eluding serious disease. In this review, we will suggest the possible association of $A B O$ group with age-related diseases and longevity taking into account the biological role of the ABO glycosyltransferases on some inflammatory mediators as adhesion molecules.
\end{abstract}

Keywords: ABO, Cancer, Cardiovascular diseases, Inflammation, Longevity

\section{Introduction}

There are accumulating evidences that the $\mathrm{ABO}$ blood antigens might play a key role in various human diseases [1]. Historically, the ABO phenotype was one of the first marker involved in cancer susceptibility [2,3], whereas the first association between Human Leukocyte Antigens (HLA) and disease was described more recently: the association involved a cross-reactive group of HLA-B antigens and Hodgkin's disease [4]. However, the identification of large numbers HLA-associated diseases counterpart our increased understanding of the genetic complexity of the HLA system and its extensive polymorphism [5], whereas data for $\mathrm{ABO}$ antigens are yet not so clear. The ABO molecules represent a complex membrane antigens widely expressed both on the surface of red blood cells (RBC) and many other cells extending the importance and the clinical significance of the $\mathrm{ABO}$ system beyond the transfusion medicine $[6,7]$.

\section{The ABO system}

The $A B O$ antigen system occurs as a result of complex carbohydrate polymorphism mosaic of glycoproteins and

\footnotetext{
* Correspondence: claudia.rizzo@unipa.it

"Unit of Transfusion Medicine, University Hospital "Paolo Giaccone", Palermo, Italy

${ }^{2}$ Department of Pathobiology and Medical and Forensic Biotechnologies, University of Palermo, Palermo, Italy

Full list of author information is available at the end of the article
}

glycolipids expressed on the surface of cells, or present in secretions, as glycan units [6,7].

The A and B antigens are inherited as Mendelian characteristics in a co-dominant autosomal fashion. These antigens are the enzymatic products of enzymes called glycosyltransferases that in turn synthesize the oligosaccharide epitopes. Thus, the A and B antigens are made by $\mathrm{A}$ and $\mathrm{B}$ glycosyltransferase, respectively (A-synthesizing 3$\alpha-\mathrm{N}$-acetylgalactosaminyltransferase and the B-synthesizing $3-\alpha-\mathrm{N}$-galactosaminyltransferase) while the $\mathrm{O}$ allele does not encode for a functional transferase. In this last case, the acceptor substrate, ( $\mathrm{H}$ antigen: Fuc alpha1- $>2$ Gal-) remains without a further modification and the $\mathrm{A}$ and $\mathrm{B}$ determinants are absent on surfaces of cells [6-8].

The A and B glycosyltransferases are type II membrane proteins located in the Golgi compartment, although soluble forms are found in plasma and other body fluids. The enzyme consists of a short transmembrane domain, a stem region and a catalytic domain that extends into the Golgi lumen. So, the A and B antigen synthesis occurs during normal glycosylation of proteins and lipids in the Golgi compartment. The precursor $\mathrm{H}$ substance is synthesized by one of two fucosyltransferases depending on the acceptor substrate used. The FUT1 gene that encodes the 2 - $\alpha$-fucosyltransferase ( $\alpha 2 \mathrm{FucT} 1)$ is mainly responsible for the synthesis of the $\mathrm{H}$ antigen on carbohydrate precursors found on RBC. The closely related FUT2 gene 
encodes a very similar 2 - $\alpha$-fucosyltransferase ( $\alpha 2$ FucT2) that is expressed in epithelial cells $[7,8]$.

As regards the organization of the $\mathrm{ABO}$ locus, the gene consists of seven coding exons and it is extended on $18 \mathrm{~kb}$ of genomic DNA. The sizes of the exons are included in a range of $28-688 \mathrm{bp}$, while the two major exons, 6 and 7, have a size of 1062 bp and contain most of the coding sequence. The single nucleotide deletion, found in a large number, but not all, of $\mathrm{O}$ alleles and responsible for the loss of the activity of the enzyme, is located in exon 6. The first of the seventh nucleotide substitutions, which distinguish the $\mathrm{A}$, and $\mathrm{B}$ transferases, resides in coding exon 6. Exon 7 contains six nucleotide substitutions, resulting in four amino acid substitutions, that differentiate the A and B transferases $[7,8]$.

$\mathrm{ABO}$ subgroups are distinguished by decreased amounts of antigens on RBC, so A2 subgroup RBC has less antigens than $\mathrm{A} 1$ subgroup (and so on for the other $\mathrm{A}$ and $\mathrm{B}$ subgroups). It is important to point out that the amount of antigens depends on glycosyltransferase activity [9].

The ABH sugars are found on lipids (approximately $10 \%$ ) and proteins (approximately 90\%) on the RBC surface as well as on many different tissues and cell types, including epithelial cells that line the lumen of the gastrointestinal, respiratory, and reproductive tracts as well as in salivary glands and skin. This wide distribution is a common feature for many of the carbohydrate blood groups, which has resulted in the term histo-blood group often being used to reflect this wide distribution. Accordingly, it has been suggested that these antigens, as the other glycoconjugates, are important mediators of intercellular adhesion and membrane signalling $[7,8,10]$.

\section{Ageing and longevity}

The ageing and longevity processes are determined by different genetic, epigenetic, stochastic and environmental factors. Among others, evidences from epidemiological studies on family of twins and long-lived individuals suggest a strong role for genetics. However, if genetics covers the $25 \%$ of the overall variation in human life span, another $25 \%$ is dependent on socio-economic factors in childhood, while adulthood and old age, including the socio-economic status and medical care, events may represent the remaining $50 \%$. In the Western world, the development of the social-economics conditions, as medical care and quality of life, are responsible of a general improvement of the health population status with a consequent reduction of the overall morbidity and mortality, resulting in an overall increase of life expectancy [11,12].

Ageing can be defined as a decline in performance and fitness with advancing age, creating difficulty in adapting to new environmental situations. The post-maturational ageing process, in fact, is characterized by a diminished homeostasis and vulnerability of the body, responsible for a reduced response to environmental stimuli and stresses that lead to increased susceptibility and vulnerability to disease. Therefore, the mortality from all causes exponentially increases with age. In Western countries, the mortality rate increases in people over the age of 65 , when compared with individuals between 25 and 44 years, because of heart disease (92 times), cancer (43 times), stroke (more than 100 times), chronic lung disease (greater than 100 times) and pneumonia and influenza (89 times), pointing out the role of the control of maintenance/repair systems as those involved in oxidative stress and immuneinflammatory responses, in the attainment of successful ageing [13-16].

Ageing is unnatural and damage is a fact of life. Ageing is not a programmed route but is a stochastic process resulting from accumulation of somatic damage implying a systemic loss of molecular fidelity. In ageing, the limited investments in maintenance and repair that are evolutionarily selected to assure reproduction and parental care brought to a minimal control of inflammation and oxidative stress. So, the ageing process is mostly stochastic, whereas the genome plays a role in determining longevity, which is regulated by the level of functional reserve reached at the time of reproductive age through natural selection. In other words, the effect of the duration of life is incidental because the main effect of the genome is to govern the events that occur until reproductive maturity [16-18].

Accordingly, demographic evidences suggest that longevity may be attained by different combinations of genes and environment with quantitative and qualitative differences in the different geographical areas where the population-specific genetic factors play a role in the longevity phenotype $[19,20]$.

In this context, the study of centenarian offspring, a group of healthy elderly people with a familiar history of longevity, has helped gerontologists to better identify the correlation between genetic profile and hope of a healthy ageing. Previous studies have reported that centenarian offspring, like their centenarian parents, have genetic and immune system advantages, which reflect a minor risk to develop major age-related diseases, such as cardiovascular diseases (CVD), hypertension or diabetes mellitus as well as cancer [21,22].

Therefore, as previously stated, it is possible to assume that longevity may be influenced by polymorphisms of genes that control the immune-inflammatory responses as well as genes that modulate cardiovascular disease and cancer [20,23-25].

Different studies performed on mice have suggested that the Major Histocompatibility Complex (MHC), known to control a variety of immune functions, is associated with the life span of the strains. Hence, several studies have been performed in humans by analysing loci that regulate the immune response, as human MHC (HLA) and killer 
cell immunoglobulin-like receptor (KIR) genes regulating the cytolytic activity of natural killer cells. On the whole, the results suggest that HLA/KIR/longevity associations are population specific, being heavily affected by the population-specific genetic and environmental history [26-29].

In addition, as previously stated, alleles associated to CVD and cancer susceptibility have been shown to be not included in the genetic background favouring longevity, at least in some population, depending on the environmental stimuli $[20,23]$.

\section{$\mathrm{ABO}$ and age related diseases}

Over the time, several studies have tried a possible association between ABO groups and diseases although with contrasting results $[1,9,30,31]$. Many of the performed studies present serious challenges because of a number of confounding factors [32]: i) the incorrect sample size leading to selection bias and false positive associations (i.e. the lack of statistical power); ii) different inclusion criteria, unsuitable mixing of data (cohort effects) referred to people of different age, incorrect control matching, i.e. lack of selection from the same target population (stratification); iii) linkage disequilibrium, i.e. the associated $\mathrm{ABO}$ group may play no direct role, and the actual disease-predisposing polymorphism may be in linkage disequilibrium with the initially reported $\mathrm{ABO}$ association, which merely acts as a marker. Therefore, we will here report only the associations that have been confirmed relating to age-related diseases, cancer and CVD.

Cancer is generally recognized as an age-related disease $[23,33]$. In fact, incidence and mortality rates of most human cancers consistently increase with age up to 90 years, although they thereafter plateau and decline. The largest number of cancer cases occur in over 65 years in both sexes: the incidence of cancer is 12-36 times higher in subjects over 65 years compared to individuals aged between 25-44 years and 2-3 times more common than people aged between $45-64$ years. The multistage model of carcinogenesis provides insight into the relationship between ageing and carcinogenesis, since ageing could be considered not so much as a determinant of cancer but as the condition, which results in a longer duration of exposure to carcinogens [23]. However, a low-grade systemic inflammation characterizes ageing and this pro-inflammatory status may underlie biological mechanisms responsible for age-related inflammatory diseases $[14,24]$. Clinical and epidemiological studies, in fact, show a strong association between chronic infections, inflammation and cancer and indicate that, even in tumours not directly linked to pathogens, the microenvironment is characterized by the presence of a smouldering inflammation, fuelled both by stromal leukocytes and senescent cells characteristic of ageing [23,24,34]. Therefore, the higher incidence of cancer in ageing could be due to pro-inflammatory state of ageing [23]. In any case, cancer and ageing are both fuelled by the accumulation of cellular damage, so they can simultaneously proceed [33].

Several studies have looked for the association between ABO blood group and cancer, however there are only evidences for pancreatic and gastric cancer [9,30,31].

The association with pancreatic cancer can be traced back to the 1960 study of Aird [35] who in 620 patients with pancreatic cancer found evidence of some strength that cancer of the pancreas is commoner in persons of group $\mathrm{A}$ than in persons of groups $\mathrm{O}$ or $\mathrm{B}$. Following this pioneering study, in the following years many studies have been performed. As reviewed by Liumbruno and Franchini $[9,30,31]$, cohort, case-control and meta-analysis studies clearly demonstrate the role of ABO blood group in pancreatic cancer. In particular, it is become clear the protective effect of $\mathrm{O}$ group and the association with $\mathrm{A} 1$ allele. The evidence that A1 allele, responsible for an increased glycosyltransferase activity, confers greater pancreatic cancer risk than A2 allele, focus on the biological role of glycans, as potential mechanism to explain the association, since glycoconjugates, such as ABO antigen, are important mediators of intercellular adhesion and membrane signalling, which are both critical to the progression and spread of malignant cells $[10,36]$.

Concerning gastric cancer, also in this case, as stated in the Introduction, the pioneering study was performed by Aird [2], which in 1953 on 3,632 patients, highlighted a $20 \%$ increase of carcinoma of the stomach in group A as compared to group $\mathrm{O}$. As discussed by Liumbruno e Franchini [9,30,31], most of the studies have confirmed that the risk of gastric cancer in blood group A is significantly higher than in non-A groups. Concerning the mechanisms, it has to point out that $\mathrm{ABO}$ blood group is a risk factor for progression towards gastric cancer in patients with Helicobacter pylori ( $\mathrm{Hp}$ ) infection, since in the gastric epithelium, the $\mathrm{ABO}$ blood groups antigens are one of the major functional receptor for $\mathrm{Hp}[36,37]$. The association seems to be highly dependent on Hp cytotoxin associated gene (CagA) status, which is responsible for the secretion of the CagA virulence protein that, injected in the host cell cytosol, plays a relevant role in the precancerous lesion development. This might account for the lack of association in studies that did not take into account the prevalence of $\mathrm{Hp}$ infection in the population under study [36].

As regards age-related CVD, an important role is played by atherosclerotic disease, one of the main causes of mortality worldwide. Atherosclerosis is a chronic, progressive, multifactorial disease mostly affecting large and mediumsized elastic and muscular arteries: fatty-streak lesions are initiated by the accumulation of monocytes in subendothelial spaces, where they develop into lipid-laden 
macrophages, otherwise known as foam cells. Currently, multiple independent pathways of evidences suggest this pathological condition as a peculiar form of inflammation, triggered by cholesterol-rich lipoproteins and other noxious factors, such as cigarette smoke, diabetes mellitus and hypertension. Inflammation seems, indeed, to be the prevalent process of atherosclerosis, evocated by multiple risk factors and responsible for the altered arterial biology associated with atherosclerosis complications $[20,38,39]$.

The initial stimulus inducing the inflammatory process has not yet been fully identified. However, endothelial dysfunction plays a crucial role in inflammation evocation. Several causes are associated with endothelial dysfunction, including the major number of traditional atherosclerosis risk factors, i.e. elevated low density lipoprotein values, free radicals caused by cigarettes smoking, hypertension, diabetes, elevated levels of homocysteine. Infections caused by Chlamydia pneumoniae, Herpes simplex virus, Cytomegalovirus and $\mathrm{Hp}$ also have been claimed to play a key factors in the disease. Thus, atherosclerosis may be considered as a characteristic response both to endothelium injury and to the consequent endothelial dysfunction. Endothelial dysfunction leads to compensatory responses modifying the normal homeostatic properties of the endothelium and favouring the expression of adhesion molecules, which, by binding to various classes of leukocytes, play a key role in the atherosclerotic process [20,38-41].

Complex interactions among the resident endothelial cells, the smooth muscle cells and the infiltrating monocytes and $\mathrm{T}$ lymphocytes determine the progression of fatty streaks into vascular lesions that block the normal blood flow and ultimately end into rupture of the atherosclerotic plaque, leading to either myocardial infarction or stroke $[20,38,39]$.

However, the inflammatory process has a strong heritable component. Thus, the analysis of the genes that are key nodes of the inflammatory response might in part clarify the pathophysiology of atherosclerosis and its complications $[14,20,24]$.

Several studies have documented the influence of $A B O$ blood groups on plasma Willebrand factor (VWF) levels, hence of factor VIII plasma levels. ABH oligosaccaride structures have been identified on the $\mathrm{N}$-linked oligosaccharide chains of VWF located in the A1 domain, which contains the binding site for platelet glycoprotein Ib. The VWF levels are approximately $25 \%$ higher in individuals who have a blood group other than $\mathrm{O}$ and it might depend on endothelial A, B glycosyltransferase enzymes, which generate $\mathrm{A}$ and $\mathrm{B}$ antigens, on the existing VWF " $\mathrm{H}$ " oligosaccharides. This addition to VWF might, in turn, influence its blood level [9,31,42-44].

On this basis, it is not surprising that a possible association between $\mathrm{CVD}$ and $\mathrm{ABO}$ blood group has been pointed out by several case-control, retrospective and meta-analysis studies. Although, most studies show an increased risk for CVD in subjects carrying non-O blood groups, there are conflicting results suggesting that the issue of the association between $\mathrm{ABO}$ blood group and CVD need further investigations [9,31]. On the other hand, large-scale genomic studies (GWAS) have revealed a central role for $\mathrm{ABO}$ antigens and blood levels of inflammatory mediators as soluble adhesion molecules, demonstrating that group $\mathrm{O}$ individuals show higher levels of inflammatory mediators. This might be due to glycosyltransferases activity, which might negatively influence shedding/cleavage of inflammatory molecules from the endothelium $[9,20,31,45,46]$, see also below. In any case, this could explain the inconsistent results obtained.

\section{$A B O$ and longevity}

$\mathrm{ABO}$ antigens have been known for a long time and yet their biological meaning is still largely obscure $[1,6]$. Based on the available knowledge of the genes involved in their biosynthesis and their tissue distribution, their polymorphism has been suggested to provide intraspecies diversity allowing to cope with diverse and rapidly evolving pathogens [1,6]. Accordingly, the different prevalence of $\mathrm{ABO}$ group genotypes among the populations has been demonstrated to be driven by malaria selection $[1,47,48]$. In the similar manner, a particular ABO blood group may contribute to favour life-extension via biologica mechanisms important for surviving or eluding serious disease [6].

There are only five reports suggesting a possible association between $\mathrm{ABO}$ blood groups and ageing/longevity features, among those only two performed on centenarians and only one performed by molecular methods. In the first one, a significant increase of A blood type was observed in the healthy elderly male population over 64 years of age from UK [49], but it is not possible to consider this study for the very low age taken into account. In a study carried out on a small sample of very longevous Turkish population, no association was found [50]; however, the validity of age claims was very questionable because birth certificates were not available, so also this study cannot be considered.

A more recent study investigated the association between blood groups and life expectancy in Japanese population [51]. The authors compared frequencies of $\mathrm{ABO}$ blood groups in 269 centenarians living in Tokyo and those in 7153 regionally matched controls. Differences between centenarians and controls and between observed and expected frequencies were investigated by Chi Square tests. Group B was observed more frequently in centenarians than in controls, suggesting that group B might be associated with exceptional longevity. The authors suggested that group B individuals are more likely to survive agerelated diseases rather than escape them, since $33 \%$ of the 
centenarians were free of age-related diseases, but this did not correlate with the group B.

In a further study, to validate these results, Brecher and Hay [52] collected data on the ABO blood groups of patients who died in a United States tertiary care hospital over a 1-year period. If group B was a marker for a longer lifespan, it would be expected that the percentage of group B patients would rise with age at the time of death and those of other blood groups would decline. A total of 772 patients were included in the study and data were presented as $\mathrm{ABO}$ proportion stratified by age. The authors found that the percentage of group $\mathrm{B}$ patients declined with age, and this result was statistically significant. None of the other blood groups showed a statistically significant increase or decrease when plotted against decade of death. Overall, these results suggest that group B is not a marker for longevity, at least in US.

We have recently investigated [53] the relationship between $A B O$ group and longevity in a small sample of homogeneous Sicilian centenarians $(\mathrm{n}=38)$ and young controls $(n=59)$. Our group of centenarians (age range 100-107) had no cardiac risk factors or other age-related diseases. The control group (age range 45-65) was recruited from blood donors and judged to be healthy on the basis of clinical history and blood tests (complete blood cell count, erythrocyte sedimentation rate, glucose, urea nitrogen, creatinine, electrolytes, C-reactive protein, liver function tests, iron, proteins, cholesterol and triglycerides). Samples were genotyped by molecular biology to determine $\mathrm{ABO}$ blood group and Chi Square analysis was used to determine the statistical significance of differences in $\mathrm{ABO}$ of centenarians and controls. Our pilot study shows a not-significant increase of A1 allele in Sicilian centenarians.

\section{Conclusions}

As previously stated, blood groups seem to influence serum level of soluble adhesion molecules in blood stream. In particular, it is interesting to note that levels of serum soluble E-selectin, which represents an inflammatory marker of several diseases, including CVD, are higher in $\mathrm{O} / \mathrm{O}$ individuals, whereas a single nucleotide polymorphism in A1 allele is associated with low levels of these inflammatory markers. A recent GWAS conducted on level of inflammatory markers in the Sardinian population highlighted the association between CVD and ABO locus and the association was established between this locus and interleukin (IL)-6 gene. Subjects homozygous for G allele in rs657152 SNP, corresponding to blood type $\mathrm{O}$ carriers, showed higher IL-6 circulating levels respect to non-O carriers, although the reason in unknown, reinforcing a relevant involvement of blood group antigens in inflammatory process. Indeed, previous studies demonstrated that a variant in $\mathrm{ABO}$ genes might explain the variation in soluble E-selectin levels [45,46,54-56].

As previously stated, several studies show that inflammatory gene variants, responsible for a low inflammatory response or a high anti-inflammatory response are associated with longevity, avoiding or delaying the onset of CVD [19-21]. In the generation of centenarians under study, the control of CVD, in fact plays a key role in the longevity attainment [19-21]. So, the Sicilian results, that need to be confirmed in a larger sample of centenarians, also taking into account the gender due to its relevance in immune-inflammatory responses [57], are in line with the previous statements. So, people carrying A1 allele should be advantaged in attaining longevity because of the lower levels of the serum soluble inflammatory marker E-selectin linked to this blood group, so avoiding or delaying cardiovascular events.

\section{Competing interests}

The authors declare that they have no competing interests.

\section{Authors' contributions}

CR drafted the paper. All authors edited the paper and approved its final version.

\section{Acknowledgements}

This work was supported by Grants from Palermo University to Calogero Caruso (FFR2012/2013 Role of Immune-Inflammatory Responses in Successful Ageing). CR is PhD student of the PhD course in Molecular Medicine directed by CC and this paper is submitted in partial fulfilment of her degree.

\section{Author details}

'Unit of Transfusion Medicine, University Hospital "Paolo Giaccone", Palermo, Italy. ${ }^{2}$ Department of Pathobiology and Medical and Forensic Biotechnologies, University of Palermo, Palermo, Italy. ${ }^{3}$ National Center for Research, Institute of Biomedicine and Molecular Immunology, Palermo, Italy. ${ }^{4}$ Department of Science and Biological, Chemical and Pharmaceutical Technologies, Institute of Biomedicine and Molecular Immunology, Palermo, Italy.

Received: 23 September 2014 Accepted: 18 October 2014 Published: 1 November 2014

\section{References}

1. Anstee DJ: The relationship between blood groups and disease. Blood 2010, 115:4635-4643.

2. Aird I, Bentall HH, Roberts JA: A relationship between cancer of stomach and the ABO blood groups. Br Med J 1953, 1:799-801.

3. Aird I, Bentall HH, Mehigan JA, Roberts JA: The blood groups in relation to peptic ulceration and carcinoma of colon, rectum, breast, and bronchus; an association between the $\mathrm{ABO}$ groups and peptic ulceration. $\mathrm{Br}$ Med J 1954, 2:315-321.

4. Amiel JL: Study of the leukocyte phenotypes in Hodgkin's disease. In Histocompatibility Testing, 1967. Edited by Curtoni ES, Mattiuz PL, Tosi MR. Copenhagen, Denmark: Munksgaard, A/S; 1967:79.

5. Howell WM: HLA and disease: guilt by association. Int $J$ Immunogenet 2014, 41:1-12

6. Moon T: An Examination of the Relationship of ABO Blood Group and Lifespan in a Hospitalized Population in the Southeastern United States, VCU Theses and Dissertations. 2014:Paper 3348.

7. Storry JR, Olsson ML: The ABO blood group system revisited: a review and update. Immunohematology 2009, 25:48-59.

8. Patnaik SK, Helmberg W, Blumenfeld OO: BGMUT: NCBI dbRBC database of allelic variations of genes encoding antigens of blood group systems. Nucleic Acids Res 2012, 40(Database issue):D1023-D1029.

9. Franchini M, Liumbruno GM: ABO blood group: old dogma, new perspectives. Clin Chem Lab Med 2013, 51:1545-1553. 
10. Hakomori S: Antigen structure and genetic basis of histo-blood groups $A$, $B$ and O: their changes associated with human cancer. Biochim Biophys Acta 1999, 1473:247-266

11. Caruso C, Passarino G, Puca A, Scapagnini G: "Positive biology": the centenarian lesson. Immun Ageing 2012, 9:5

12. Kolovou G, Barzilai N, Caruso C, Sikora E, Capri M, Tzanetakou IP, Bilianou H, Avery P, Katsiki N, Panotopoulos G, Franceschi C, Benetos A, Mikhailidis DP: The challenges in moving from ageing to successful longevity. Curr VasC Pharmacol 2014, 12:659-661.

13. Troen BR: The biology of aging. Mt Sinai J Med 2003, 70:3-22.

14. Vasto S, Candore G, Balistreri CR, Caruso M, Colonna-Romano G, Grimaldi MP, Listi F, Nuzzo D, Lio D, Caruso C: Inflammatory networks in ageing, age-related diseases and longevity. Mech Ageing Dev 2007, 128:83-91.

15. Kirkwood TB: Understanding ageing from an evolutionary perspective. J Intern Med 2008, 263:117-127.

16. Avery P, Barzilai N, Benetos A, Bilianou H, Capri M, Caruso C, Franceschi C, Katsiki N, Mikhailidis DP, Panotopoulos G, Sikora E, Tzanetakou IP, Kolovou G: Ageing, longevity, exceptional longevity and related genetic and non genetics markers: panel statement. Curr Vasc Pharmacol 2014, 12:662-673.

17. Hayflick L: Entropy explains aging, genetic determinism explains longevity, and undefined terminology explains misunderstanding both. PLOS Genet 2007, 3:e220.

18. López-Otín C, Blasco MA, Partridge L, Serrano M, Kroemer G: The hallmarks of aging. Cell 2013, 153:1194-1217.

19. Capri M, Salvioli S, Monti D, Caruso C, Candore G, Vasto S, Olivieri F Marchegiani F, Sansoni P, Baggio G, Mari D, Passarino G, De Benedictis G, Franceschi C: Human longevity within an evolutionary perspective: the peculiar paradigm of a post-reproductive genetics. Exp Gerontol 2008, 43:53-60.

20. Incalcaterra E, Accardi G, Balistreri CR, Caimi G, Candore G, Caruso M, Caruso C: Pro-inflammatory genetic markers of atherosclerosis. Curr Atheroscler Rep 2013, 15:329.

21. Balistreri CR, Accardi G, Buffa S, Bulati M, Martorana A, Candore G, Colonna-Romano G, Lio D, Caruso C: Centenarian offspring: a model for understanding longevity. Curr VasC Pharmacol 2014, 12:718-725.

22. Balistreri CR, Candore G, Accardi G, Bova M, Buffa S, Bulati M, Forte Gl, Listì F, Martorana A, Palmeri M, Pellicanò M, Vaccarino L, Scola L, Lio D, Colonna-Romano G: Genetics of longevity. Data from the studies on Sicilian centenarians. Immun Ageing 2012, 9:8.

23. Vasto S, Carruba G, Lio D, Colonna-Romano G, Di Bona D, Candore G, Caruso C: Inflammation, ageing and cancer. Mech Ageing Dev 2009, 130:40-45.

24. Cevenini E, Caruso C, Candore G, Capri M, Nuzzo D, Duro G, Rizzo C, Colonna-Romano G, Lio D, Di Carlo D, Palmas MG, Scurti M, Pini E, Franceschi C, Vasto S: Age-related inflammation: the contribution of different organs, tissues and systems. How to face it for therapeutic approaches. Curr Pharm Des 2010, 16:609-618.

25. Vasto S, Scapagnini G, Bulati M, Candore G, Castiglia L, Colonna-Romano G, Lio D, Nuzzo D, Pellicano M, Rizzo C, Ferrara N, Caruso C: Biomarkes of aging. Front Biosci (Schol Ed) 2010, 2:392-402.

26. Caruso C, Candore G, Romano GC, Lio D, Bonafé M, Valensin S, Franceschi C Immunogenetics of longevity. Is major histocompatibility complex polymorphism relevant to the control of human longevity? A review of literature data. Mech Ageing Dev 2001, 122:445-462.

27. Caruso C, Candore G, Colonna Romano G, Lio D, Bonafé M, Valensin S, Franceschi C: HLA, aging, and longevity: a critical reappraisal. Hum Immunol 2000, 61:942-949.

28. Listì F, Caruso C, Colonna-Romano G, Lio D, Nuzzo D, Candore G: HLA and KIR frequencies in Sicilian Centenarians. Rejuvenation Res 2010, 13:314-318

29. Rea IM, Maxwell LD, McNerlan SE, Alexander HD, Curran MD, Middleton D, Ross OA: Killer Immunoglobulin-like Receptors (KIR) haplogroups A and B track with Natural Killer Cells and Cytokine Profile in Aged Subjects: Observations from Octo/Nonagenarians in the Belfast Elderly Longitudinal Free-living Aging Study (BELFAST). Immun Ageing 2013, 10:35.

30. Liumbruno GM, Franchini M: Hemostasis, cancer, and ABO blood group: the most recent evidence of association. J Thromb Thrombolysis 2014, 38:160-166.

31. Liumbruno GM, Franchini M: Beyond immunohaematology: the role of the ABO blood group in human diseases. Blood Transfus 2013, 11:491-499.
32. Rizzo C, Accardi G, Caruso C: Genetic variation in HLA and susceptibility to acute myeloid leukemia. Acta Haematol 2014, 133:162-163.

33. Serrano M, Blasco MA: Cancer and ageing: convergent and divergent mechanisms. Nat Rev Mol Cell Biol 2007, 8:715-722.

34. Campisi J: Aging, cellular senescence and cancer. Annu Rev Physiol 2013, 75:685-705

35. Aird I, Lee DR, Roberts IA: ABO blood groups and cancer of oesophagus, cancer of pancreas, and pituitary adenoma. Br Med J 1960, 1:1163-1166.

36. Rizzato C, Kato I, Plummer M, Muñoz N, Stein A, Jan van Doorn L, Franceschi S, Canzian M: Risk of advanced gastric precancerous lesions in Helicobacter pylori infected subjects is influenced by $A B O$ blood group and CagA status. Int J Cancer 2013, 133:315-322.

37. Wolpin BM, Kraft P, Xu M, Steplowski E, Olsson ML, Arslan AA, Bueno-deMesquita HB, Gross M, Helzlsouer K, Jacobs EJ, LaCroix A, Petersen G, Stolzenberg-Solomon RZ, Zheng W, Albanes D, Allen NE, Amundadottir L, Austin MA, Boutron-Ruault MC, Buring JE, Canzian F, Chanock SJ, Gaziano JM, Giovannucci EL, Hallmans G, Hankinson SE, Hoover RN, Hunter DJ, Hutchinson A, Jacobs KB, et al: Variant ABO blood group alleles, secretor status, and risk of pancreatic cancer: results from the pancreatic cancer cohort consortium. Cancer Epidemiol Biomarkers Prev 2010, 19:3140-3149.

38. Libby P, Ridker PM, Hansson GK: Progress and challenges in translating the biology of atherosclerosis. Nature 2011, 473:317-325.

39. Libby P: Inflammation in atherosclerosis. Arterioscler Thromb Vasc Biol 2012 32:2045-2051.

40. Messner B, Bernhard D: Smoking and cardiovascular disease: mechanisms of endothelial dysfunction and early atherogenesis. Arterioscler Thromb Vasc Biol 2014, 34:509-515.

41. Rader DJ, Hovingh GK: HDL and cardiovascular disease. Lancet 2014, 384:618-625.

42. O'Donnell J, Laffan MA: The relationship between $A B O$ histo-blood group, factor VIII and von Willebrand factor. Transfus Med 2001, 11:343-351.

43. Matsui T, Titani K, Mizuochi T: Structures of the asparagine linked oligosaccharide chains of human von Willebrand factor. Occurrence of blood group A, B, and H(O) structures. J Biol Chem 1992, 267:8723-8731.

44. Sodetz JM, Pizzo SV, McKee PA: Relationship of sialic acid to function and in vivo survival of human factor VIII/von Willebrand factor protein. J Biol Chem 1977, 252:5538-5546.

45. Paterson AD, Lopes-Virella MF, Waggott D, Boright AP, Hosseini SM, Carter RE, Shen E, Mirea L, Bharaj B, Sun L, Bull SB: Diabetes Control and Complications Trial/Epidemiology of Diabetes Interventions and Complications Research Group. Genome-wide association identifies the $A B O$ blood group as a major locus associated with serum levels of soluble E-selectin. Arterioscler Thromb Vasc Biol 2009, 29:1958-1967.

46. Kiechl S, Paré G, Barbalic M, Qi L, Dupuis J, Dehghan A, Bis JC, Laxton RC, Xiao Q, Bonora E, Willeit J, Xu Q, Witteman JC, Chasman D, Tracy RP, Ballantyne CM, Ridker PM, Benjamin EJ, Ye S: Association of variation at the $A B O$ locus with circulating levels of soluble intercellular adhesion molecule-1, soluble P-selectin, and soluble E-selectin: a meta-analysis. Circ Cardiovasc Genet 2011, 4:681-686.

47. Marionneau S, Cailleau-Thomas A, Rocher J, Le Moullac-Vaidye B, Ruvoën N, Clément $\mathrm{M}$, Le Pendu J: $\mathrm{ABH}$ and Lewis histo-blood group antigens, a model for the meaning of oligosaccharide diversity in the face of a changing world. Biochimie 2001, 83:565-573.

48. Fry AE, Griffiths MJ, Auburn S, Diakite M, Forton JT, Green A, Richardson A, Wilson J, Jallow M, Sisay-Joof F, Pinder M, Peshu N, Williams TN, Marsh K, Molyneux ME, Taylor TE, Rockett KA, Kwiatkowski DP: Common variation in the $A B O$ glycosyltransferase is associated with susceptibility to severe Plasmodium falciparum malaria. Hum Mol Genet 2008, 17:567-576

49. Murray S: ABO groups and Rh genotypes in the elderly. Br Med J 1961 2:1472-1474

50. Sturgeon P, Beller S, Bates E: Study of blood group factors in longevity J Gerontol 1969, 24:90-94.

51. Shimizu K, Hirose N, Ebihara Y, Arai Y, Hamamatsu M, Nakazawa S, Masui Y, Inagaki H, Gondo Y, Fujimori J, Kanno Y, Konishi K, Kitagawa K: Blood type B might imply longevity. Exp Gerontol 2004, 39:1563-1565.

52. Brecher ME, Hay SN: ABO blood type and longevity. Am J Clin Pathol 2011, 135:96-98.

53. Vasto S, Caruso C, Castiglia L, Duro G, Monastero R, Rizzo C: Blood group does not appear to affect longevity a pilot study in centenarians from Western Sicily. Biogerontology 2011, 12:467-471. 
54. Barbalic M, Dupuis J, Dehghan A, Bis JC, Hoogeveen RC, Schnabel RB, Nambi V, Bretler M, Smith NL, Peters A, Lu C, Tracy RP, Aleksic N, Heeriga J, Keaney JF Jr, Rice K, Lip GY, Vasan RS, Glazer NL, Larson MG, Uitterlinden AG, Yamamoto J, Durda P, Haritunians T, Psaty BM, Boerwinkle E, Hofman A, Koenig W, Jenny NS, Witteman JC, et al: Large-scale genomic studies reveal central role of ABO in SP-selectin and sICAM-1 levels. Hum Mol Genet 2010, 19:1863-1872.

55. Naitza S, Porcu E, Steri M, Taub DD, Mulas A, Xiao X, Strait J, Dei M, Lai S, Busonero F, Maschio A, Usala G, Zoledziewska M, Sidore C, Zara I, Pitzalis M, Loi A, Virdis F, Piras R, Deidda F, Whalen MB, Crisponi L, Concas A, Podda C, Uzzau S, Scheet P, Longo DL, Lakatta E, Abecasis GR, Cao A, et al: A genome-wide association scan on the levels of markers of inflammation in Sardinians reveals associations that underpin its complex regulation. PLoS Genet 2012, 8:e1002480.

56. Karakas M, Baumert J, Kleber ME, Thorand B, Dallmeier D, Silbernagel G, Grammer TB, Rottbauer W, Meisinger C, Illig T, März W, Koenig W: A variant in $\mathrm{ABO}$ gene explains the variation in soluble E-Selectin levels - Results from dense genotyping in two independent populations. PLoS One 2012, 7:e51441.

57. Caruso C, Accardi G, Virruso C, Candore G: Sex, gender and immunosenescence: a key to understand the different lifespan between men and women? Immun Ageing 2013, 16:10.

doi:10.1186/1742-4933-11-16

Cite this article as: Rizzo et al:: Possible role of ABO system in age-related diseases and longevity: a narrative review. Immunity \& Ageing 2014 11:16.

\section{Submit your next manuscript to BioMed Central and take full advantage of:}

- Convenient online submission

- Thorough peer review

- No space constraints or color figure charges

- Immediate publication on acceptance

- Inclusion in PubMed, CAS, Scopus and Google Scholar

- Research which is freely available for redistribution 